\title{
Protective effects of GV1001 on myocardial ischemia-reperfusion injury
}

\author{
JI-EUN CHANG ${ }^{1}$, HYUN JUN KIM ${ }^{1}$, SANGHOON JHEON $^{1,2}$ and CHEONG LIM ${ }^{1,2}$ \\ ${ }^{1}$ Department of Thoracic and Cardiovascular Surgery, \\ Seoul National University Bundang Hospital, Seongnam-si, Gyeonggi-do $13620 ;{ }^{2}$ Department of Thoracic and \\ Cardiovascular Surgery, Seoul National University College of Medicine, Seoul 03080, Republic of Korea
}

Received October 19, 2016; Accepted August 2, 2017

DOI: $10.3892 / \mathrm{mmr} .2017 .7528$

\begin{abstract}
The potential cardioprotective effects of the novel vaccine peptide GV1001 were evaluated in myocardial ischemia-reperfusion injury induced rat models. GV1001 is a human telomerase reverse transcriptase derived peptide, which has been reported to possess both anti-tumor and anti-inflammatory effects. The normal saline (control group) and various concentrations $(0.001-10 \mathrm{mg} / \mathrm{kg}$ ) of GV1001 were administered directly to the right ventricle anterior wall before induction of ischemia. The was induced by Tightening the snare around the left anterior descending coronary artery for $40 \mathrm{~min}$, before releasing the snare for $10 \mathrm{~min}$ induced the myocardial ischemia-reperfusion injury and was conducted in Sprague-Dawley rats. The area at risk, histology, apoptotic cells, neutrophils and inflammatory cytokines were analyzed from the excised heart tissue following myocardial ischemia-reperfusion injury. The area at risk was protected by concentrations of GV1001 equal to or higher than $0.01 \mathrm{mg} / \mathrm{kg}$. At $0.1 \mathrm{mg} / \mathrm{kg}$ and higher concentrations of GV1001, the hemorrhage in the heart was attenuated, while severe congestion was reported in the control group. Apoptotic cells, myeloperoxidase activity and inflammatory cytokines [tumor necrosis factor (TNF)- $\alpha$ and interleukin (IL)-6] revealed decreased levels in a dose-dependent manner with respect to GV1001 concentration. The group treated with $10 \mathrm{mg} / \mathrm{kg} \mathrm{GV1001} \mathrm{demonstrated}$ $59.73 \%$ apoptotic cells $(\mathrm{P}<0.001), 48.14 \%$ neutrophil contents $(\mathrm{P}<0.001), 55.63 \%$ TNF- $\alpha(\mathrm{P}<0.01)$ and $42.35 \%$ IL-6 $(\mathrm{P}<0.01)$ levels, compared with the control group. The novel vaccine peptide GV1001 provided protective effects on myocardial ischemia-reperfusion injury and, therefore, it should be
\end{abstract}

Correspondence to: Professor Cheong Lim, Department of Thoracic and Cardiovascular Surgery, Seoul National University Bundang Hospital, 82 Gumi-ro 173 Beon-Gil, Bundang-gu, Seongnam-si, Gyeonggi-do 13620, Republic of Korea

E-mail: mluemoon@snubh.org

Key words: myocardial ischemia-reperfusion injury, anti-inflammatory agent, GV1001, human telomerase reverse transcriptase, cardioprotection considered as an alternative potential anti-inflammatory agent for myocardial ischemia-reperfusion injury.

\section{Introduction}

Myocardial ischemia-reperfusion (IR) injury often occurs following cardiovascular surgery (1). This results from coronary blood supply, which is produced by thrombosis or coronary atherosclerotic plaques (2). The imbalance between oxygen supply and demand from the ischemic organ facilitates the production of oxygen free radicals, inflammatory cytokines and other proinflammatory mediators, which leads to severe tissue damage $(3,4)$.

During cardiac surgery, myocardial protection techniques, such as cardioplegia and hypothermia, are applied to reduce the severity of the myocardial IR injury. The lowered temperature protects the ischemic heart by reducing cellular metabolism and the oxygen demand of the tissue. It also increases tolerance of metabolic waste accumulation (5). However, there still remains the problem of IR injury-related cardiac dysfunction.

GV1001 is a novel vaccine peptide derived from the human telomerase reverse transcriptase (hTERT) corresponding to amino acids 611-626 of hTERT (6). It is a 16-amino acid peptide with the following sequence; Glu-Ala-Arg-Pro-AlaLeu-Leu-Thr-Ser-Arg-Leu-Arg-Phe-Ile-Pro-Lys (7). Since hTERT is a well-known cancer target that is overexpressed in most human cancer tissues (8), GV1001 was initially developed as an anticancer drug. It has been proved to be effective for various cancer treatments, such as non-small cell lung cancer $(9,10)$, pancreatic cancer $(8,11)$, hepatocellular carcinoma (12), melanoma $(13,14)$ and B-cell chronic lymphocytic leukemia (15). Since GV1001 has been also known to possess anti-inflammatory effects, various pre-clinical studies are ongoing to evaluate the anti-inflammatory effects and their underlying mechanisms from disease models. It was reported that GV1001 decreases the pro-inflammatory cytokines [tumor necrosis factor (TNF)- $\alpha$, interleukin (IL)-1 $\beta$ and IL-6] by suppressing p38 mitogen-activated protein kinase (MAPK) and nuclear factor (NK) $\mathrm{\kappa B}$ activation following enolase 1 (ENO1) stimulation (16). ENO1 induces inflammation through p38 MAPK and NF- $\kappa B$ signaling pathway activation. NF- $\mathrm{kB}$ regulates inflammation through transcription regulation. 
Furthermore, p38 MAPK is the key regulator of proinflammatory cytokine.

The authors previously identified the anti-inflammatory effect of GV1001 on IR injury in a rat lung transplantation model (17). Koo et al (18) also studied the protective effects of GV1001 against renal IR injury model. In the present study, focusing on modulating the inflammatory response, the authors investigated the myocardial protective effects of GV1001 in an IR injury rat model.

\section{Materials and methods}

Animals. The study protocols were approved by the Institutional Animal Care and Use Committee of Seoul National University Bundang Hospital (BA1307-133/060-01; Seoul, Korea). A total of 105 10-week old male Sprague-Dawley rats (Orient Bio Inc., Seongnam, Korea) weighing 300-350 g were used in the study. All animals were housed in a $12 \mathrm{~h}$ light-dark cycle and allowed water and food ad libitum.

Chemicals. GV1001 was a gift from GemVax \& KAEL Co., Ltd. (Seongnam, Korea).

Cardiac ischemia-reperfusion injury model. The cardiac ischemia-reperfusion injury model was induced based on the previous study (19). The rats were anesthetized by an intraperitoneal injection of Rompun $(23.3 \mathrm{mg} / \mathrm{ml})$ and Zoletil $(50 \mathrm{mg} / \mathrm{ml})(1: 2$; $1 \mathrm{ml} / \mathrm{kg}$ ) mixture. During the experiments, the body temperature was monitored via a rectal thermometer probe and maintained at $37 \pm 0.5^{\circ} \mathrm{C}$ by a heating pad and lamp. Then, the rat was intubated through a tracheostomy with a 14-gauge intravenous catheter (B. Braun Melsungen, Melsungen, Germany) and tied with 4-0 silk ligature (Ethicon Inc., Cornelia, GA, USA). The ventilator (Harvard Apparatus, Holliston, MA, USA) was connected at a respiratory rate of 60 breaths $/ \mathrm{min}$, a tidal volume of $10 \mathrm{ml} / \mathrm{kg}$, a positive end-expiratory pressure of $2 \mathrm{~cm} \mathrm{H}_{2} \mathrm{O}$, and a fraction of inspired oxygen of 1.0. The chest was opened by midline sternotomy and the heart was exposed. Before the induction of IR injury, normal saline (control) or the determined concentration $(0.001,0.01,0.1,1,5$ or $10 \mathrm{mg} / \mathrm{kg}$ ) of GV1001 was injected directly through the right ventricle anterior wall using a 30-gauge needle and a $1 \mathrm{ml}$ syringe (BD Biosciences, Franklin Lakes, NJ, USA), for a total of 7 different treatment groups. Around the mid-to-distal third of the left anterior descending (LAD) coronary artery was identified with 6-0 polyprophylene suture (Ethicon Inc.) for subsequent snaring. Then, the suture was passed through a tube using a tourniquet and ischemic injury was achieved by tightening the snare and clamping the tube with a mosquito clamp. The ischemic zone was confirmed by its pale color. At $40 \mathrm{~min}$, following induction of ischemic injury, reperfusion was performed by releasing the snare for $10 \mathrm{~min}$.

Assessment of area at risk. At the end of the reperfusion, the LAD coronary artery was religated and $0.5 \mathrm{ml} 5 \%$ Evans blue solution was infused through the inferior vena cava to visualize the area at risk (AAR). The rat was sacrificed and the heart was excised, transversely sliced into $2 \mathrm{~mm}$-thick sections from the apex to the base. The slices were incubated in $1 \%$ triphenyltetrazolium chloride (TTC) at $37^{\circ} \mathrm{C}$ for $20 \mathrm{~min}$ to identify the infarct area. Then the samples were kept in $10 \%$ formalin solution to enhance the color contrast. The AAR and the left ventricle area (LA) were analyzed by computerized planimetry (Image J, version 1.48; National Institutes of Health, Bethesda, MD, USA), respectively ( $\mathrm{n}=3$ for each group). All reagents were purchased from Sigma-Aldrich; Merck KGaA (Darmstadt, Germany).

Histological analysis. Hematoxylin and eosin (H\&E) staining was performed for the histological analysis. As stated previously, the rat was euthanized following reperfusion and the heart was excised immediately and rinsed twice with cold normal saline. The central regions of the AAR from the left ventricle were separated and fixed in $10 \%$ formalin. Then the samples were embedded in paraffin and sectioned into $5 \mu \mathrm{m}$-thick slices. The severity of hemorrhage was compared.

Detection of apoptotic cells. The apoptotic cells were determined by terminal deoxynucleotidyl transferase dUTP nick end labeling (TUNEL) assay. The paraffin block samples, which were prepared from H\&E stain step, were used for the assay. The analysis was performed to label the apoptotic cells with a commercial kit (S7100; EMD Millipore, Billerica, MA, USA) following the manufacturer's protocol. Counterstaining was performed with $2 \%$ methyl green. Terminal deoxynucleotidyl transferase (TdT)-positive nuclei were stained dark brown while TdT-negative nuclei showed a light green color. A pathologist who was blind to the study randomly selected and examined four fields per each slide. TUNEL positive cells (TdT-stained nuclei) were determined and divided by the total amount of cells under a light microscope (BX43; Olympus Corporation, Tokyo, Japan; $\mathrm{n}=4$ for each group).

Myeloperoxidase determination. The myeloperoxidase (MPO) assay was performed to detect neutrophil accumulation. Following reperfusion, the rat was sacrificed and the heart was removed immediately and rinsed twice with cold normal saline. The central regions of the AAR from the left ventricle were rapidly frozen in liquid nitrogen and stored at $-80^{\circ} \mathrm{C}$. Neutrophils were determined using an MPO assay kit (ab9535; Abcam, Cambridge, MA, USA) according to the manufacturer's protocol ( $\mathrm{n}=4$ for each group).

Cytokine analysis. The heart was removed immediately, as before, and rinsed twice with cold normal saline. The central regions of the AAR from the left ventricle were frozen in liquid nitrogen and stored at $-80^{\circ} \mathrm{C}$. The concentrations of TNF- $\alpha$ and IL- 6 were measured by commercial ELISA kit (RTA00 and R6000B; R\&D Systems, Inc., Minneapolis, MN, USA; $n=4$ for each group).

Statistical analysis. All data were presented as means \pm standard deviation. The statistical significance between the two groups was determined by using Student's t-test. $\mathrm{P}<0.05$ was considered to indicate a statistically significant difference.

\section{Results}

Determination of AAR. To determine the prevention effect of GV1001 on cardiac IR injury, Evans blue and TTC staining 
were applied. Representative images of heart sections are presented in Fig. 1A. The dark blue stained area indicates the Evans blue solution-perfused region, which denotes the non-ischemic region. The red area indicates the non-perfused, ischemic region, which denotes the AAR. The pale white area within the AAR represents infarcted, necrotic region, where the cardiomyocytes have died. The infarct area was identified only in the control and the $0.001 \mathrm{mg} / \mathrm{kg} \mathrm{GV} 1001$-treated group.

The percentage of AAR/LA was calculated for each group (Fig. 1B). AAR was protected by a high concentration of GV1001 (0.01 mg/kg or higher). The control group indicated $77.77 \pm 13.01 \%$ AAR/LA, while the $10 \mathrm{mg} / \mathrm{kg}$ GV1001-treated group reported the most decreased value $(63.03 \pm 19.82 \%)$. No significant difference was observed between the control group and any other experimental groups.

Histological analysis. The representative images of H\&E stained AAR sections are presented in Fig. 2. GV1001-treated groups displayed a reduced degree of hemorrhage compared with the normal saline-treated group, which demonstrated a high degree of hemorrhage.

Cardiomyocyte apoptosis assay. A TUNEL stain assay was performed to determine the apoptotic cells in the IR injury induced heart tissue. The TUNEL positive cells were stained with dark brown and considered to be apoptotic cells (Fig. 3A). The apoptotic cells were quantitatively counted and expressed as \% of total cell counts (Fig. 3B). Compared with the control group (75.25 $\pm 3.91 \%)$, GV1001-treated groups reported dose-dependent decreased levels of the TUNEL positive cells. The $0.01 \mathrm{mg} / \mathrm{kg}(63.06 \pm 6.64 \%$; $\mathrm{P}<0.05), 0.1 \mathrm{mg} / \mathrm{kg}(61.93 \pm 4.26 \% ; \mathrm{P}<0.01), 1 \mathrm{mg} / \mathrm{kg}$ (52.44 $\pm 8.22 \% ; \mathrm{P}<0.01), 5 \mathrm{mg} / \mathrm{kg}(47.95 \pm 8.93 \% ; \mathrm{P}<0.01)$, and $10 \mathrm{mg} / \mathrm{kg}(44.95 \pm 7.59 \%$; $\mathrm{P}<0.001) \mathrm{GV} 1001$-treated groups reported significantly decreased apoptotic cells in the IR injury-induced heart.

Determination of neutrophil contents in cardiac tissue. To evaluate the anti-inflammatory effect of GV1001 on cardiac IR injury, MPO activity was measured as a marker of neutrophil expression. The authors determined the MPO activity from the excised AAR tissue samples. As displayed in Fig. 4, MPO activities decreased in a GV1001 dose-dependent manner compared with the control group $(58.75 \pm 8.83 \mathrm{mU} / \mathrm{ml}) .1 \mathrm{mg} / \mathrm{kg}(37.04 \pm 2.97 \mathrm{mU} / \mathrm{ml} ; \mathrm{P}<0.01)$, $5 \mathrm{mg} / \mathrm{kg}(32.08 \pm 2.63 \mathrm{mU} / \mathrm{ml} ; \mathrm{P}<0.01)$ and $10 \mathrm{mg} / \mathrm{kg}$ (28.28 $\pm 2.18 \mathrm{mU} / \mathrm{ml} ; \mathrm{P}<0.001) \mathrm{GV} 1001$ treated group reported significantly decreased neutrophil contents in the IR injury-induced heart.

Cytokine analysis. For further other confirmation of the anti-inflammatory effects of GV1001 on cardiac IR injury, inflammatory cytokines from the excised AAR zone were analyzed. Fig. 5A and B present a GV1001 dose-dependent decrease in the levels of TNF- $\alpha$ and IL-6. For TNF- $\alpha$ analysis (Fig. 5A), the $0.1 \mathrm{mg} / \mathrm{kg}$ $(117.62 \pm 10.55 \mathrm{pg} / \mathrm{m} ; \mathrm{P}<0.05), 1 \mathrm{mg} / \mathrm{kg}(93.21 \pm 25.12 \mathrm{pg} / \mathrm{ml}$; $\mathrm{P}<0.05), 5 \mathrm{mg} / \mathrm{kg}(79.68 \pm 28.47 \mathrm{pg} / \mathrm{ml} ; \mathrm{P}<0.01)$ and $10 \mathrm{mg} / \mathrm{kg}$ $(75.41 \pm 21.76 \mathrm{pg} / \mathrm{ml} ; \mathrm{P}<0.01) \mathrm{GV} 1001$ treated groups presented

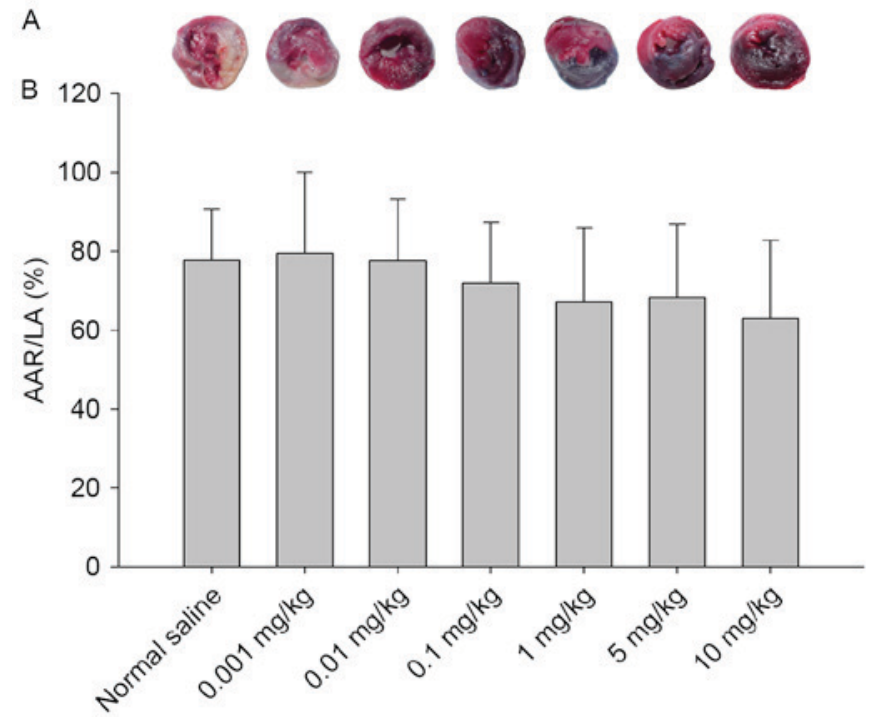

Figure 1. Cardiac ischemia-reperfusion induced risk area. (A) Representative images of Evans blue and triphenyltetrazolium chloride-stained heart sections. The dark blue stained area represents the non-ischemic region, the red area indicates the ischemic region, and the white area within the AAR depicts the infarct region. (B) The ratio of the AAR to the LA was calculated for each group. The data are presented as means \pm standard deviation. No significant difference was observed between the control group and any other experimental group ( $\mathrm{n}=3$ for each group). AAR, area at risk; LA, left ventricle area.

significantly decreased levels compared with the control group $(135.56 \pm 9.86 \mathrm{pg} / \mathrm{ml})$.

For IL-6 analysis (Fig. 5B), significantly decreased levels were identified in the $0.1 \mathrm{mg} / \mathrm{kg}$ $(275.71 \pm 27.62 \mathrm{pg} / \mathrm{ml} ; \mathrm{P}<0.05), 1 \mathrm{mg} / \mathrm{kg}(211.97 \pm 38.74 \mathrm{pg} / \mathrm{m}$; $\mathrm{P}<0.01), 5 \mathrm{mg} / \mathrm{kg}(185.76 \pm 29.25 \mathrm{pg} / \mathrm{ml} ; \mathrm{P}<0.01)$ and $10 \mathrm{mg} / \mathrm{kg}$ $(138.20 \pm 62.13 \mathrm{pg} / \mathrm{ml} ; \mathrm{P}<0.01) \mathrm{GV} 1001-$ treated groups compared with the control group $(326.34 \pm 28.67 \mathrm{pg} / \mathrm{ml})$.

\section{Discussion}

To overcome the limitations of present cardioprotective techniques, various pre-clinical approaches have been made. Some research has focused on modulating the inflammatory response. Shimamoto et al (20) evaluated the effect of eritoran, a specific Toll-like receptor 4 (TLR4) antagonist, on myocardial IR injury. TLR4 was suggested as a proinflammatory receptor in IR injury. TLR2 also serves a key role in myocardial IR injury and Arslan et al (21) studied the effect of anti-TLR2 antibody. The four transmembrane adenosine receptors $\left(\mathrm{A}_{1}, \mathrm{~A}_{2 \mathrm{~A}}, \mathrm{~A}_{2 \mathrm{~B}}\right.$ and $\left.\mathrm{A}_{3}\right)$ are associated with cardiac protection. These receptors are expressed in the immune system and modulate the effects of adenosine (22). Adenosine was studied to reduce myocardial IR injury using adenosine-receptor-based therapy $(23,24)$.

In the present study, the authors confirmed the myocardial protective effect of the novel vaccine peptide GV1001 on an IR injury animal model. This was conducted by establishing a stable myocardial IR injury model by performing $40 \mathrm{~min}$ of ischemic injury and 10 min of reperfusion in Sprague-Dawley rats. When the ischemic time was shorter than $40 \mathrm{~min}$, the ischemic injury was insufficient for evaluation. In addition, 


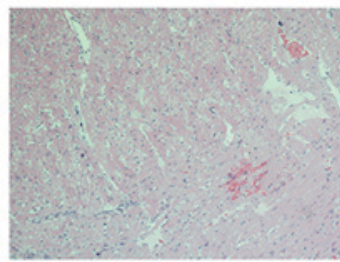

Normal saline

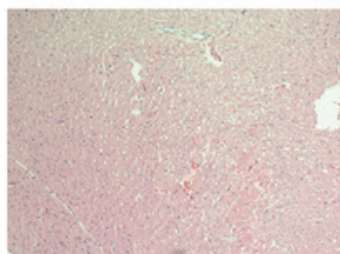

$0.1 \mathrm{mg} / \mathrm{kg}$

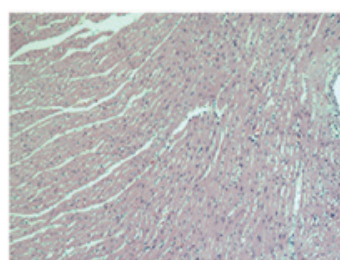

$10 \mathrm{mg} / \mathrm{kg}$

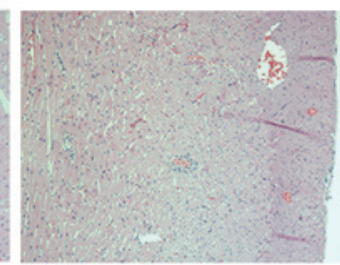

$0.001 \mathrm{mg} / \mathrm{kg}$

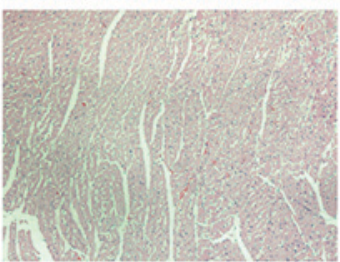

$1 \mathrm{mg} / \mathrm{kg}$

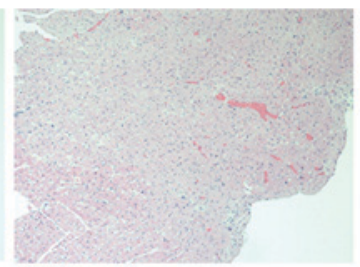

$0.01 \mathrm{mg} / \mathrm{kg}$

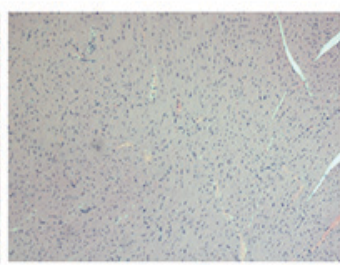

$5 \mathrm{mg} / \mathrm{kg}$

Figure 2. Representative histological images of hematoxylin and eosin stained heart sections following ischemia-reperfusion injury. The hemorrhage was attenuated in the GV1001-treated groups compared with the control group.

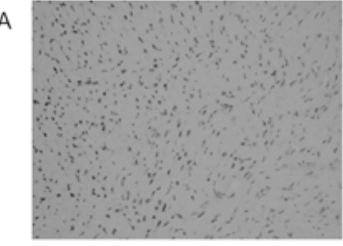

Normal saline

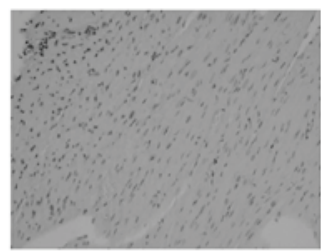

GV1001 $0.1 \mathrm{mg} / \mathrm{kg}$

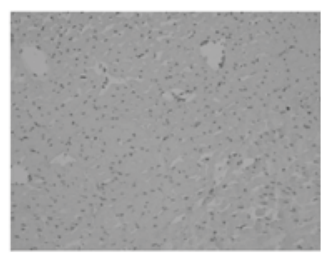

GV1001 $10 \mathrm{mg} / \mathrm{kg}$

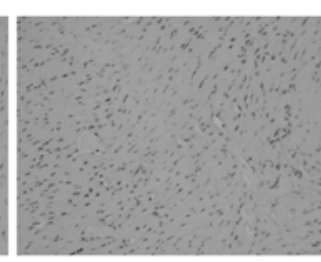

GV1001 $0.001 \mathrm{mg} / \mathrm{kg}$

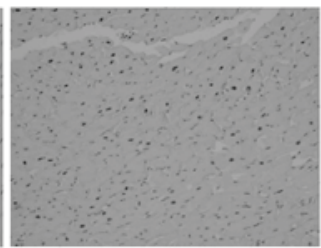

$\mathrm{GV} 10011 \mathrm{mg} / \mathrm{kg}$

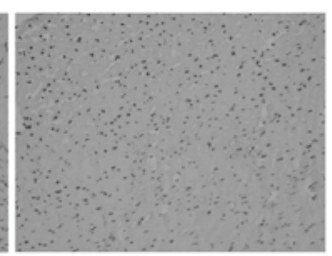

GV1001 $0.01 \mathrm{mg} / \mathrm{kg}$

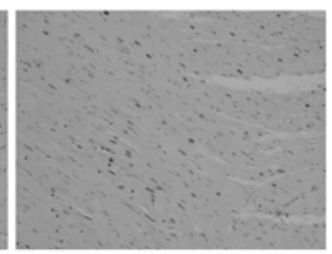

GV10015 mg/kg
B

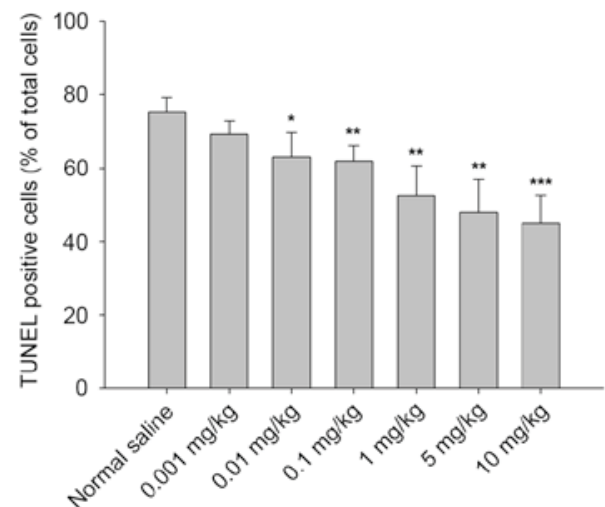

Figure 3. Cardiac ischemia-reperfusion induced myocyte apoptosis. (A) Representative images of cardiomyocyte TUNEL stain. The TUNEL positive cells were stained dark brown and considered to be apoptotic cells. (B) Quantitative analysis of TUNEL positive cells per total cells. The data are presented as means \pm standard deviation. ${ }^{*} \mathrm{P}<0.05,{ }^{* *} \mathrm{P}<0.01,{ }^{* * *} \mathrm{P}<0.001$ vs. normal saline control group ( $\mathrm{n}=4$ for each group). TUNEL, terminal deoxynucleotidyl transferase dUTP nick end labeling.

when the ischemic time was longer than $40 \mathrm{~min}$, cardiac arrest occurred leading to death. It was important to determine the proper ischemic and reperfusion time providing the appropriate damage. To maintain the constant strength when tightening the snare was also a critical point in preparing the uniform myocardial IR injury models. $10 \mathrm{~min}$ of reperfusion time was the maximum stable survival periods in the established model. Due to the strong ischemia induction, the reperfusion time was not too long. However, according to these data, our myocardial IR injury model was damaged enough to express 


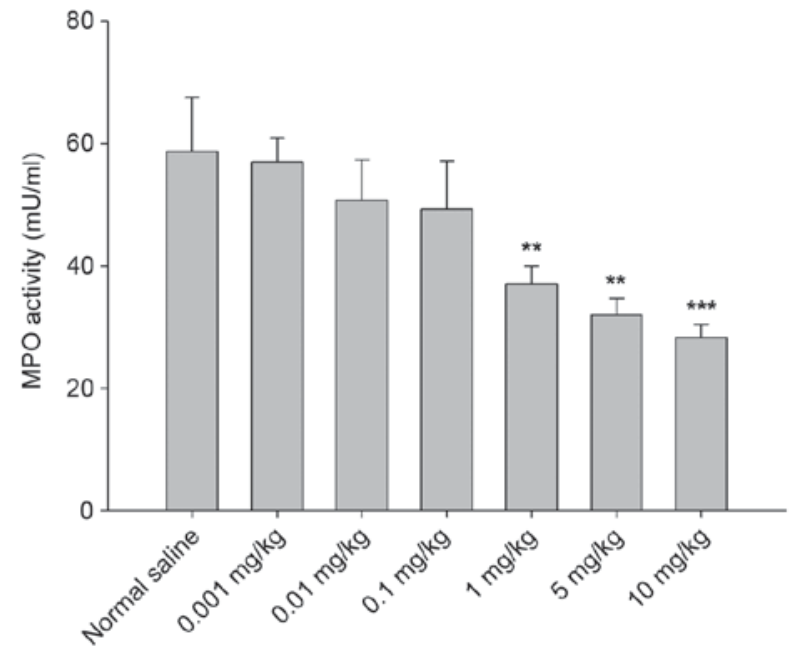

Figure 4. Heart MPO activity analysis following cardiac ischemia-reperfusion injury induction. The data are presented as means \pm standard deviation. ${ }^{* * *} \mathrm{P}<0.01,{ }^{* * * *} \mathrm{P}<0.001$ vs. normal saline control group ( $\mathrm{n}=4$ for each group). MPO, myeloperoxidase.

apoptotic cells, neutrophils and inflammatory cytokines from the ischemic zone.

To evaluate the cardioprotective effects of GV1001 on IR injury, AAR analysis, histological analysis, TUNEL assay, MPO assay and inflammatory cytokine analysis were performed. Since the recommended dose of GV1001 for inflammation has not yet been determined, the authors tried various concentrations $(0.001,0.01,0.1,1,5$ and $10 \mathrm{mg} / \mathrm{kg})$ GV1001 for the study.

The AAR and the infarct area were determined by Evans blue and TTC staining (Fig. 1). The infarct area was only identified in the normal saline and the $0.001 \mathrm{mg} / \mathrm{kg} \mathrm{GV1001}$ treated groups as the authors speculat that the induced myocardial IR injury was not severe enough to express complete infarction. Furthermore, induced mild infarction was prevented by a high concentration of GV1001 $(0.01 \mathrm{mg} / \mathrm{kg}$ or higher).

When severe damage occurs to the endothelium, extravasation of blood into the interstitum leads to intramyocardial hemorrhage (25). Though the quantitative analysis was not easy, based on the representative images, $0.1 \mathrm{mg} / \mathrm{kg}$ and higher concentrations of GV1001 presented attenuated congestion, while severe bleeding was observed in the control group (Fig. 2).

Interestingly, apoptotic cells (Fig. 3), MPO activity (Fig. 4) and inflammatory cytokines (TNF- $\alpha$ and IL-6; Fig. 5) reported GV1001 dose-dependent decreased levels. The $10 \mathrm{mg} / \mathrm{kg}$ GV1001 pre-treated group presented $59.73 \%$ apoptotic cells, $48.14 \%$ neutrophil contents, $55.63 \%$ TNF- $\alpha$ and $42.35 \%$ IL-6 levels compared with the control group. The inflammatory cytokines, such as TNF- $\alpha$ and IL-6, are well known mediators of inflammation in early IR injury, which regulates myocyte survival or apoptosis (26). In previous studies, pretreatment with eritoran (TLR4 antagonist) in a myocardial IR injury model attenuated $29.37 \%$ TNF- $\alpha$ and $28.50 \%$ IL-6 compared with the control group (20). When the Toll/IL-1R (TIR)/BB-loop mimetic AS-1 is administered in myocardial IR injury model, TNF- $\alpha$ and IL- 6 were reduced
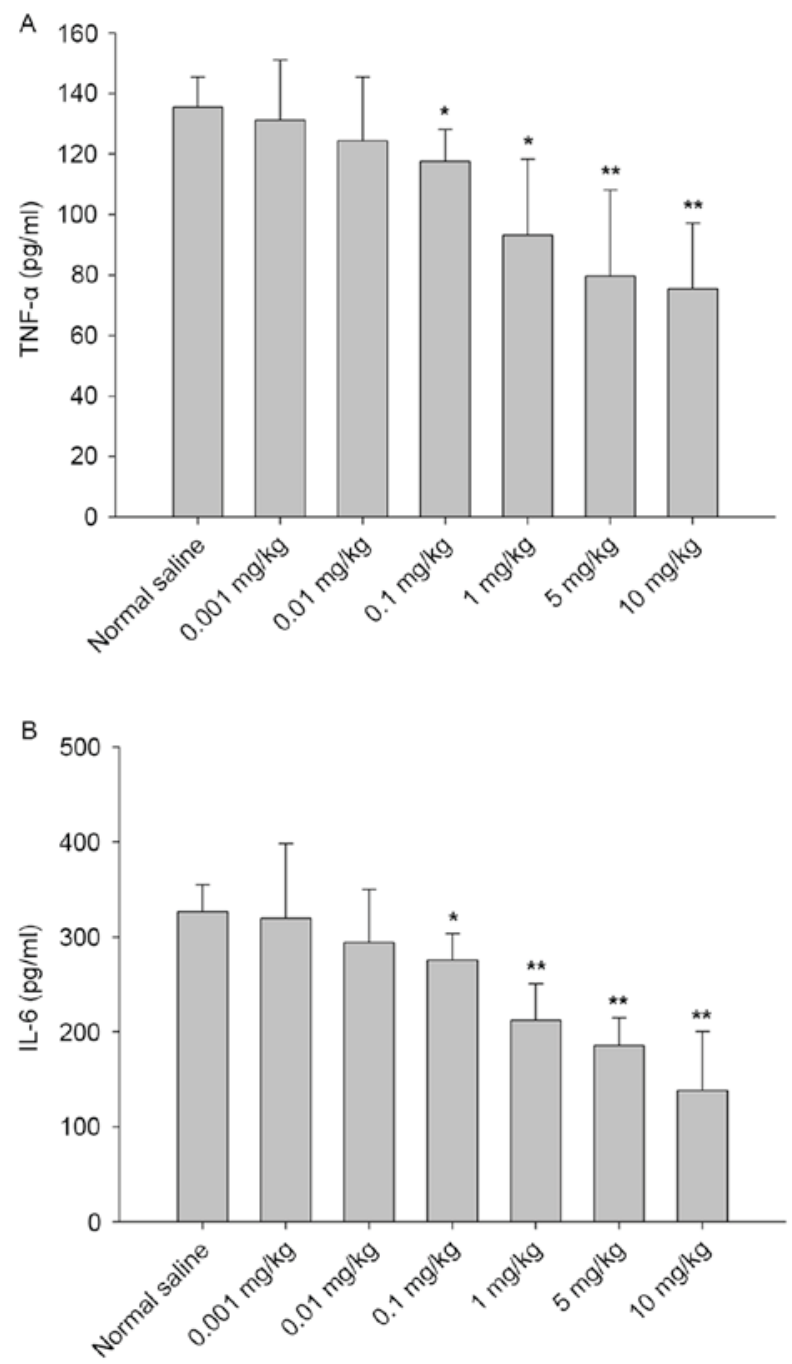

Figure 5. The analysis of (A) TNF- $\alpha$ and (B) IL-6 in heart tissue following cardiac ischemia-reperfusion injury induction. The data are presented as means \pm standard deviation. ${ }^{*} \mathrm{P}<0.05,{ }^{* *} \mathrm{P}<0.01$ vs. control group $(\mathrm{n}=4$ for each group). TNF- $\alpha$, tumor necrosis factor- $\alpha$; IL, interleukin.

by 30.0 and $38.7 \%$, respectively, compared with the control group (27). Though the animal models and the protocols that were adopted in the studies were not identical, GV1001 presented the most attenuated inflammatory cytokine levels compared with the previous reports. As the proinflammatory cytokines are the index of inflammation induced by IR injury, these data suggested that GV1001 effectively protects against myocardial IR injury.

Protein/peptide-based cancer vaccines are known to stimulate immune response (28). Since the hTERT participates in telomere length maintenance, it serves as an attractive therapeutic target in cancer, anti-aging, and various diseases $(29,30)$. The anti-inflammatory effect of GV1001 has been proved by previous studies. The GV1001 treatment reduced neutrophil and macrophage infiltration in renal IR injury-induced mice (19). The inhibitory effect of GV1001 in rheumatoid arthritis mice model was also evaluated (31). In a previous report of the authors, adding GV1001 to the lung preservation and flushing solutions also provided potential protective effects against IR injury in a rat lung transplantation model (18). In the 
present study, neutrophils, reperfusion edema, and inflammatory cytokines were significantly decreased in the GV1001 pre-treated lungs compared with the non-treated lungs. These results strongly support the anti-inflammatory effects of GV1001.

However, the current study has some limitations. First, the reperfusion time was short. For further investigation, pigs should be used for the myocardial IR injury models to increase the reperfusion time. Secondly, the distribution of GV1001 in the heart was not clearly verified. The drug administration was performed through the right ventricle anterior wall. This transmyocardial injection was made for the vascular distribution of the drug with avoiding any direct damage to the left ventricle surface. However, further analysis of drug distribution should be performed.

In conclusion, the novel vaccine peptide GV1001 provided myocardial protective effects against IR injury and therefore it can be considered as an alternative potential anti-inflammatory agent for myocardial IR injury.

\section{Acknowledgements}

The present study was supported by a GemVax \& KAEL Co., Ltd. Research fund (grant no. 800-20130369). The authors would also like to thank J. Patrick Barron, Professor Emeritus, Tokyo Medical University and Adjunct Professor, Seoul National University Bundang Hospital for his pro bono editing of this manuscript.

\section{References}

1. Boyle EM, Pohlman TH, Cornejo CJ and Verrier ED Ischemia-reperfusion injury. Ann Thorac Surg 64 (Suppl): S24-S30, 1997.

2. Buja LM: Myocardial ischemia and reperfusion injury. Cardiovasc Pathol 14: 170-175, 2005.

3. Jordan JE, Zhao ZQ and Vinten-Johansen J: The role of neutrophils in myocardial ischemia-reperfusion injury. Cardiovasc Res 43: 860-878, 1999.

4. Liu Q, Li J, Jubair S, Wang D, Luo Y, Fan D and Janicki JS: Sparstolonin B attenuates hypoxia-induced apoptosis, necrosis and inflammation in cultured rat left ventricular tissue slices. Cardiovasc Drugs Ther 28: 433-439, 2014.

5. Hale SL and Kloner RA: Mild hypothermia as a cardioprotective approach for acute myocardial infarction: Laboratory to clinical application. J Cardiovasc Pharmacol Ther 16: 131-139, 2011.

6. Inderberg-Suso EM, Trachsel S, Lislerud K, Rasmussen AM and Gaudernack G: Widespread CD4 ${ }^{+}$T-cell reactivity to novel hTERT epitopes following vaccination of cancer patients with a single hTERT peptide GV1001. Oncoimmunology 1: 670-686, 2012.

7. Stevenson CL: Advances in peptide pharmaceuticals. Curr Pharm Biotechnol 10: 122-137, 2009.

8. Bernhardt SL, Gjertsen MK, Trachsel S, Møller M, Eriksen JA, Meo M, Buanes T and Gaudernack G: Telomerase peptide vaccination of patients with non-resectable pancreatic cancer: A dose escalating phase I/II study. Br J Cancer 95: 1474-1482, 2006.

9. Brunsvig PF, Aamdal S, Gjertsen MK, Kvalheim G, Markowski-Grimsrud CJ, Sve I, Dyrhaug M, Trachsel S, Møller M, Eriksen JA and Gaudernack G: Telomerase peptide vaccination: A phase I/II study in patients with non-small cell lung cancer. Cancer Immunol Immunother 55: 1553-1564, 2006.

10. Brunsvig PF, Kyte JA, Kersten C, Sundstrøm S, Møller M, Nyakas M, Hansen GL, Gaudernack G and Aamdal S: Telomerase peptide vaccination in NSCLC: A phase II trial in stage III patients vaccinated after chemoradiotherapy and an 8-year update on a phase I/II trial. Clin Cancer Res 17: 6847-6857, 2011.

11. Middleton G, Ghaneh P, Costello E, Greenhalf W and Neoptolemos JP: New treatment options for advanced pancreatic cancer. Expert Rev Gastroenterol Hepatol 2: 673-696, 2008.
12. Greten TF, Forner A, Korangy F, N'Kontchou G, Barget N, Ayuso C, Ormandy LA, Manns MP, Beaugrand M and Bruix J: A phase II open label trial evaluating safety and efficacy of a telomerase peptide vaccination in patients with advanced hepatocellular carcinoma. BMC Cancer 10: 209, 2010.

13. Kyte JA, Gaudernack G, Dueland S, Trachsel S, Julsrud L and Aamdal S: Telomerase peptide vaccination combined with temozolomide: A clinical trial in stage IV melanoma patients. Clin Cancer Res 17: 4568-4580, 2011.

14. Hunger RE, Kernland Lang K, Markowski CJ, Trachsel S, Møller M, Eriksen JA, Rasmussen AM, Braathen LR and Gaudernack G: Vaccination of patients with cutaneous melanoma with telomerase-specific peptides. Cancer Immunol Immunother 60: 1553-1564, 2011.

15. Kokhaei P, Palma M, Hansson L, Osterborg A, Mellstedt H and Choudhury A: Telomerase (hTERT 611-626) serves as a tumor antigen in B-cell chronic lymphocytic leukemia and generates spontaneously antileukemic, cytotoxic T cells. Exp Hematol 35: 297-304, 2007.

16. Choi J, Kim H, Kim Y, Jang M, Jeon J, Hwang YI, Shon WJ, Song YW, Kang JS and Lee WJ: The anti-inflammatory effect of GV1001 mediated by the downregulation of ENO1-induced pro-inflammatory cytokine production. Immune Netw 15: 291-303, 2015.

17. Chang JE, Kim HJ, Yi E, Jheon S and Kim K: Reduction of ischaemia-reperfusion injury in a rat lung transplantation model by low-concentration GV1001. Eur J Cardiothorac Surg 50: 972-979, 2016.

18. Koo TY, Yan JJ and Yang J: Protective effect of peptide GV1001 against renal ischemia-reperfusion injury in mice. Transplant Proc 46: 1117-1122, 2014.

19. Yaoita H, Ogawa K, Maehara K and Maruyama Y: Attenuation of ischemia/reperfusion injury in rats by a caspase inhibitor. Circulation 97: 276-281, 1998.

20. Shimamoto A, Chong AJ, Yada M, Shomura S, Takayama H, Fleisig AJ, Agnew ML, Hampton CR, Rothnie CL, Spring DJ, et al: Inhibition of Toll-like receptor 4 with eritoran attenuates myocardial ischemia-reperfusion injury. Circulation 114 (1 Suppl): I270-I274, 2006.

21. Arslan F, Smeets MB, O'Neill LA, Keogh B, McGuirk P, Timmers L, Tersteeg C, Hoefer IE, Doevendans PA, Pasterkamp G and de Kleijn DP: Myocardial ischemia/reperfusion injury is mediated by leukocytic Toll-like receptor- 2 and reduced by systemic administration of a novel anti-Toll-like receptor-2 antibody. Circulation 121: 80-90, 2010.

22. Haskó G, Linden J, Cronstein B and Pacher P: Adenosine receptors: Therapeutic aspects for inflammatory and immune diseases. Nat Rev Drug Discov 7: 759-770, 2008.

23. Pitarys CJ II, Virmani R, Vildibill HD Jr, Jackson EK and Forman MB: Reduction of myocardial reperfusion injury by intravenous adenosine administered during the early reperfusion period. Circulation 83: 237-247, 1991.

24. Janier MF, Vanoverschelde JL and Bergmann SR: Adenosine protects ischemic and reperfused myocardium by receptor-mediated mechanisms. Am J Physiol 264: H163-H170, 1993.

25. Hausenloy DJ and Yellon DM: Myocardial ischemia-reperfusion injury: A neglected therapeutic target. J Clin Invest 123: 92-100, 2013.

26. Nian M, Lee P, Khaper N and Liu P: Inflammatory cytokines and postmyocardial infarction remodeling. Circ Res 94: 1543-1553, 2004.

27. Cao Z, Hu Y, Wu W, Ha T, Kelley J, Deng C, Chen Q, Li C, Li J and Li Y: The TIR/BB-loop mimetic AS-1 protects the myocardium from ischaemia/reperfusion injury. Cardiovasc Res 84: 442-451, 2009.

28. Disis ML: Mechanism of action of immunotherapy. Semin Oncol 41 (Suppl 5): S3-S13, 2014.

29. Mazzola P, Radhi S, Mirandola L, Annoni G, Jenkins M, Cobos E and Chiriva-Internati M: Aging, cancer, and cancer vaccines. Immun Ageing 9: 4, 2012.

30. Martínez P and Blasco MA: Telomeric and extra-telomeric roles for telomerase and the telomere-binding proteins. Nat Rev Cancer 11: 161-176, 2011.

31. Choi I, Choi J, Kim J, Oh SY, Kim S and Lee E: AB0125 the effect of Gv1001, a peptide vaccine, in animal model of rheumatoid arthritis. Annals Rheumat Dis 73: 845, 2014. 